\title{
FRENTE A “O ESPELHO" DE MACHADO E DE GUIMARÃES ROSA
}

\section{FACE TO "THE MIRROR" FROM MACHADO AND FROM GUIMARAES ROSA}

\author{
Prof". Edna Maria F. S. Nascimento* \\ Prof ${ }^{a}$.Dra . Maria Célia Leonel ${ }^{* *}$
}

RESUMO: Embora a crítica machadiana e a rosiana já tenha se debruçado sobre essas narrativas, isoladamente, ou por meio de comparação, acreditamos haver alguns aspectos desses contos que merecem ser ainda explorados. Assim, o artigo propõe-se a comparar os dois contos homônimos de Machado de Assis e de Guimarães Rosa, procurando observar os pontos de convergência e os de divergência no que diz respeito à importância das narrativas na produção de cada um dos escritores, na concepção sobre o tema, na construção da história, na escolha dos narradores.

PALAVRAS-CHAVE: Machado de Assis, Guimarães Rosa, conto, espelho, comparação.

ABSTRACT: Despite the critic of Machado de Assis and Guimarães Rosa have already devoted hard analysis to these narratives, alone, or by means of comparison, we believe that there are some aspects about these short stories which still deserve to be deeply explored. Therefore, this article proposes to compare these two homonymous short stories of Machado de Assis and Guimarães Rosa, aiming the observation of the convergent and divergent points regarding the importance of the narratives within each writer's production, in the conception on the theme, in history construction, in the choice of the narrators.

KEY WORDS: Machado de Assis, Guimarães Rosa, short story, mirror, comparison.

\footnotetext{
* Professora Doutora e Coordenadora do Programa de Pós Graduação da UNIFRAN

* Professora Doutora da UNESP - Araraquara
} 



\section{FRENTE A “O ESPELHO” DE MACHADO \\ E DE GUIMARÃES ROSA}

Cada criatura humana traz duas almas consigo: uma que olha de dentro para fora, outra que olha de fora para dentro... Espantem-se à vontade, podem ficar de boca aberta, dar de ombros, tudo; não admito réplica.

(Machado de Assis, "O espelho")

Se me permite, espero, agora, sua opinião, mesma, do senhor, sobre tanto assunto. Solicito os reparos que se digne dar-me, a mim, servo do senhor, recente amigo, mas companheiro no amor da ciência, de seus transviados acertos e de seus esbarros titubeados. Sim?

(Guimarães Rosa, "O espelho")

"Ao belo Narciso, Tirésias havia predito que ele viveria apenas enquanto a si mesmo não se visse”. (ROSA, 1972, p. 72). Sua imagem, entrevista no espelho da água, poderia representar a morte. Para os povos antigos e para quem supõe que o reflexo da pessoa é a alma, o espelho inspira receio supersticioso: ela pode, no espelho, recolher-se. Muitos são os conceitos impressos na palavra "espelho" - representação, ícone, reflexibilidade, alma, que nos conduzem a valores como vida, morte, medo, subjetividade, alteridade.

Neste estudo, colocamo-nos frente a dois espelhos, o de Machado de Assis e o de Guimarães Rosa e comparamos as concepções desses escrito- 
res relativamente a esse tema e a alguns de seus aspectos composicionais, como o tratamento do narrador. Como se trata de autores muito distantes no tempo e com estilos bastante diferentes, pode-se considerar que se trata de universos literários distintos. O título, reiterado nos contos, abre o diálogo entre esses textos que partem de uma cena enunciativa - o momento presente -, para remontar ao passado. Na narrativa machadiana, dá-se o retorno a um acontecimento passado, que marcou a personagem principal e, na composição rosiana, o protagonista-narrador recupera seu percurso da mocidade à maturidade, quando são revividos fatos essenciais que exigem reflexão. Em ambos, o mote é o espelho.

No conhecido ensaio "Esquema de Machado de Assis", Antonio Candido (1970, p. 23), vincula "O espelho" - publicado em Papéis avulsos em 1882 -, à questão fundamental da obra machadiana que é a da identidade, "da divisão do ser ou do desdobramento da personalidade, estudado por Augusto Meyer". É de 1935 a reflexão de Meyer (1975) sobre o conto em pauta que se reflete na "Apresentação" de Eugênio Gomes (1973, p. 13), aos contos machadianos da Coleção Nossos Clássicos. Comentando os textos alegóricos de Machado de Assis, em que se enquadra essa composição, o crítico estabelece um diálogo entre tal narrativa e outras que têm como característica uma filosofia sub specie ludis e que desenvolvem idéias contidas no conto "Teoria do medalhão", que foi publicado em 1881, e no romance Memórias póstumas de Brás Cubas, do mesmo ano. Na citação que recortamos da "Apresentação", Gomes (1973, p. 13-14), explicita a concepção machadiana de medalhão e dá-nos o percurso da retomada de tal noção em vários textos machadianos:

Em que consiste a teoria do medalhão que um pai irônico procura transmitir ao filho quando este chega à maioridade? Em manter, para um perfeito convívio social, as exterioridades brilhantes e vazias que fazem desse convívio a bemaventurança de tantos indivíduos: a fatuidade, a carência de idéias próprias, a preocupação absorvente com coisas e fatos frívolos, o vocabulário e idéias de empréstimo, o gosto da publicidade, com o conseqüente horror à solidão. $\mathrm{O}$ que significa esse horror em um pobre de espírito vê-se no conto "Só" (1885); o falso esplendor de uma personalidade feita de fumo e estultícia é o tema de "O Diplomático" (1884), enquanto "Evolução", também deste ano, mostra um perfeito arquétipo de vulgar apropriador de idéias alheias, entusiasta do Progresso. A alegoria da alma exterior n' "O espelho" é por igual um desdobramento 
específico da "teoria do medalhão", cujos efeitos já estavam aliás difundidos nas Memórias Póstumas de Brás Cubas.

Todas essas obras citadas por Gomes são da década de 80 do século XIX, que, segundo esse crítico e muitos outros, é a fase culminante do conto machadiano, quando predomina o humor irônico.

De todo modo, na mesma direção de Meyer e Gomes temos a leitura de Alfredo Bosi (1999, p. 102) - publicada no Brasil em 1982 e que tem como origem um estudo feito para uma antologia da Biblioteca de Ayacucho de Caracas -, sintetizada por ele mesmo: "'O espelho' é matriz de uma certeza machadiana que poderia formular-se assim: só há consistência no desempenho do papel social; aquém da cena pública a alma humana é dúbia e veleitária”.

A favor da posição dos críticos mencionados, lembramos que, no conto "O espelho", ao título, que condensa figurativamente o assunto que vai ser tratado, é dado o subtítulo que o expande tematicamente: "Esboço de uma nova teoria da alma humana". A "nova teoria" é de fato, exposta na narrativa.

Nela, o espelho constrói-se como uma expansão configuradora da alma humana, ou melhor, da "alma exterior", elaborada por Jacobina, que não quer discussão sobre a questão em pauta, propondo-se apenas a exemplificar a sua teoria:

- Nem conjetura, nem opinião, redargüiu ele [Jacobina]; uma ou outra pode dar lugar a dissentimento, e, como sabem, eu não discuto. Mas, se querem ouvir-me calados, posso contar-lhes um caso de minha vida, em que ressalta a mais clara demonstração acerca da matéria de que se trata. Em primeiro lugar, não há uma só alma, há duas... [...] uma que olha de dentro para fora, outra que olha de fora para dentro... (ASSIS, 1973, p. 25-26)

Para melhor explicar aos seus atentos ouvintes o que entende por alma exterior, além de outros exemplos, o protagonista cita uma frase de Shylock e a comenta:

A alma exterior daquele judeu eram os seus ducados; perdê-los equivalia a morrer. "Nunca mais verei o meu ouro, diz ele a Tubal; é um punhal que me enterras no coração". Vejam bem esta frase; a perda dos ducados, alma exterior, era a morte para ele. (ASSIS, 1973, p. 26). 
Juntamente com as situações exemplares, o protagonista afirma que a alma humana não é sempre a mesma. Todas essas proposições servem como introdução para o caso ocorrido com ele próprio. Aos 25 anos, Jacobina, moço pobre, fora nomeado alferes da Guarda Nacional. De Joãozinho, como era chamado em família, passa a ser o alferes. A importância da patente recebida é bastante reforçada, quando, a convite de uma tia, vai passar uns dias no sítio dela, levando a farda como ela havia lhe solicitado com insistência. Para a Tia Marcolina, ele torna-se o "Senhor Alferes" com direito a todas as honrarias: "Eu pedia-lhe que me chamasse Joãozinho, como dantes; e ela abanava a cabeça, bradando que não, que era o 'senhor Alferes"'. (ASSIS, 1973, p. 28).

Esse tratamento enaltecedor permite a observação: "fizeram em mim uma transformação, que o natural sentimento da mocidade ajudou e completou [...] O alferes eliminou o homem" (ASSIS, 1973, p. 29), ficando uma parte mínima de humanidade:

Aconteceu então que a alma exterior, que era dantes o sol, o ar, o campo, os olhos das moças, mudou de natureza, e passou a ser a cortesia e os rapapés da casa, tudo o que me falava do posto, nada do que me falava do homem. [...] Era exclusivamente alferes. (ASSIS, 1973, p. 29)

Tia Marcolina, a principal personagem a proporcionar ao jovem alferes as condições que sustentavam a natureza da sua alma exterior, deixa o sítio para acudir uma filha que estava à morte, ficando, no local, apenas os poucos escravos da casa que, com o correr do tempo, também o abandonam.

Vendo-se totalmente só, sem nenhum fôlego humano, sente-se um defunto andante, um sonâmbulo, um boneco mecânico. Só o sono lhe dá alívio, pois,

[...] eliminando a necessidade de uma alma exterior, deixava atuar a alma interior. Nos sonhos, fardava-me orgulhosamente, no meio da família e dos amigos, que me elogiavam o garbo, que me chamavam de alferes [...] e tudo isso me fazia viver. (ASSIS, 1973, p. 33)

Um dia, resolve olhar no espelho e relata o que vê: "não me estampou a figura nítida e inteira, mas vaga, esfumada, difusa, sombra de sombra" (ASSIS, 1973, p. 34). Com medo, quer ir embora, começa a vestir-se, 
lembra-se de colocar a farda de alferes e olha-se no espelho. Eis de novo a sua imagem refletida: "o vidro reproduziu então a figura integral; nenhuma linha de menos, nenhum contorno diverso; era eu mesmo, o alferes, que achava, enfim, sua alma exterior .” (ASSIS, 1973, p. 144).

O espelho, em Machado de Assis, como visto no conto e na crítica, reflete a alma exterior, que é a opinião alheia, a imagem que somos para os outros. Trata-se de uma concepção fechada, de que o conto é uma ilustração, como comenta Meyer (1975, p. 66):

Só existem as almas exteriores, bovarizadas, mascaradas, e para elas, que só navegam na sabedoria da superfície, é melhor não sondar a profundidade terrível do homem. Quem tira a farda, quem tenta ver o que há além da fantasmagoria organizada em seu proveito pela inconsciência vital, sente a vertigem de si mesmo e de tudo, acaba falando sozinho diante do espelho, como o Alferes Jacobina. Aliás, logo torna a vesti-la, num momento reflexo de defesa.

O conto "O espelho" de João Guimarães Rosa, por sua vez, faz parte de um conjunto de vinte e uma pequenas narrativas de Primeiras estórias (1972), publicado em 1962. Essa composição ocupa o lugar central entre os contos da coletânea, o que tem chamado a atenção da crítica. É de 1977 o livro Bruxo da linguagem no Grande sertão em que Consuelo Albergaria (p. 68), sobre essa posição, afirma que as demais narrativas dispõem-se simetricamente em relação a "O espelho", o que permite que "[...] quer pelo tema, quer pelo assunto, os demais vinte contos se apresentem numa ordem inversa e rebatida", levando a ver, no volume, "a estrutura de um triângulo virtual”. A noção de centro é cara a Guimarães Rosa e vários ensaios críticos têm refletido sobre essa questão no que se refere a Grande sertão: veredas.

Heloisa Vilhena de Araújo, por exemplo, denomina O espelho: contribuição ao estudo de Guimarães Rosa (1998) seu estudo sobre Primeiras estórias, tomando o conto em questão e o tema de Narciso para examinar o modo como, na obra rosiana, emerge o "helenismo cristianizado" ou o "helenismo em via de cristianização". A abertura do seu estudo remete à importância do centro na produção rosiana, considerando que a novela "O recado do morro", central na coletânea Corpo de baile, "é o ponto de partida que agrupa ao seu redor os demais contos, que os estrutura, que os emparelham que os balanceia, que define o tema, sempre complexo, que os unifica, formando um corpo orgânico." (ARAUJO, 1998, p. 19). Vale lembrar que, 
com a tripartição de Corpo de baile na década de sessenta do século passado, a possibilidade de se visualizar "O recado do morro" como composição central do conjunto de novelas ficou prejudicada.

O estudo mais abrangente de Primeiras estórias, de Ana Paula Pacheco (2006) analisa, no último capítulo, "As formas do espelho - dilemas da representação", a narrativa que nos ocupa, examinando entre outras, a questão do duplo e a relação com o texto homônimo de Machado de Assis.

No conto rosiano, relata-se uma experiência que induz a intuições e reflexões sobre o que é, na verdade, o espelho, ou seja, o problema da identidade da psique humana. O texto começa com travessão e, como em Grande sertão: veredas e "Meu tio o Iauretê" de Estas estórias, é um diálogo pela metade, ou seja, o discurso pressupõe um interlocutor culto como no único romance rosiano: "O senhor, por exemplo, que sabe e estuda, suponho nem tenha idéia do que seja na verdade - um espelho?” (ROSA, 1972, p. 71).

O enunciador começa a narrativa afirmando que há espelhos "bons" e "maus" e a partir dessa constatação, interroga: "Como é que o senhor, eu, os restantes próximos, somos, no visível?” (ROSA, 1972, p. 71). Relaciona ainda uma série de exemplos que poderiam comprovar como, de fato, são os homens e, logo a seguir, desmonta-os. Quanto às fotografias, diz: "Ainda que tirados de imediato um após outro, os retratos sempre serão entre si muito diferentes" (ROSA, 1972, p. 71, grifo do autor); quanto às máscaras, "Valem, grosso modo, para o falquejo das formas, não para o explodir da expressão, o dinamismo fisionômico" (ROSA, 1972, p. 71); a respeito da nossa percepção relativamente a outras pessoas, há deformação de ordem psicológica: "Os olhos, por enquanto, são a porta do engano." (ROSA, 1972, p. 72).

Todas essas ponderações servem como introdução para o fato que vai narrar: o encontro, ocorrido no cotidiano e involuntariamente, de um moço - ele próprio, personagem qualificado como "contente", "vaidoso" -, consigo mesmo, em um espelho:

Foi num lavatório de edifício público, por acaso [...] E o que enxerguei, por instante, foi uma figura, perfil humano, desagradável ao derradeiro grau, repulsivo senão hediondo [...] causava-me ódio e susto, eriçamento, espavor. E era - logo descobri... era eu, mesmo! (ROSA, 1972, p. 73).

A partir daí, o narrador-protagonista começa a procurar o que define como o "eu por detrás de mim", "a minha vera forma” por meio de vários 
artifícios, em diferentes posições e expressões de sentimento - ira, medo, orgulho, alegria, tristeza - frente ao espelho. Queria ir além da máscara nele refletida, além do rosto externo, que é formado de diversos componentes. Principiou por bloquear a onça, elemento animal que lhe seria correspondente: "E, então, eu teria que, após dissociá-lo meticulosamente, aprender a não ver, no espelho, os traços que em mim recordavam o grande felino. Atirei-me a tanto." (ROSA, 1972, p. 75, grifo do autor)

O segundo componente apagado é o elemento hereditário, "as parecenças com os pais e avós”. Desaparece, ainda, o que se deve ao contágio das paixões "[...] o que ressaltava das desordenadas pressões psicológicas transitórias" (ROSA, 1972, p. 76), o que "materializa idéias e sugestões de outrem", além de "interesses efêmeros". Até que, um dia,

Simplesmente lhe digo que me olhei num espelho e não me vi. Não vi nada. Só o campo, liso, às vácuas, aberto como o sol, água limpíssima, à dispersão da luz, tapadamente tudo. Eu não tinha formas, rosto? Apalpei-me, em muito. Mas, o invisto. O ficto. O sem evidência física. Eu era - o transparente contemplador?... Tirei-me. Aturdi-me, a ponto de me deixar cair na poltrona. (ROSA, 1972, p. 76).

Sem rosto externo, sem olhos, o protagonista quer voltar a tê-los, quer se espelhar, porque uma dúvida o assalta: "Seria eu um... des-almado?" (ROSA, 1972, p. 77). Anos mais tarde, depois de sofrimentos grandes e de amar, relata:

Sim, vi, a mim mesmo, de novo, meu rosto, um rosto; não este, que o senhor razoavelmente me atribui. Mas o ainda-nem-rosto-quase, de nascimento abissal... E era não mais que: rostinho de menino, de menos-que-menino, só. Só. (ROSA, 1972, p. 78).

O conto rosiano termina com a questão: "Será este nosso desengonço e mundo o plano - intersecção de planos - onde se completam de fazer as almas?" (ROSA, 1972, p. 78). Respondida a questão afirmativamente, a vida sendo "experiência extrema e séria", bastando o despojamento de tudo o que obstrui o seu crescimento, surge espaço para novo questionamento: "Você chegou a existir?" e, com ele, a destruição da concepção de vida como "agradável acaso". 
Os três parágrafos finais d'“O espelho" rosiano são espelho do que é a sua narrativa: uma interrogação, a dúvida figurativizada e não resolvida. Ao interlocutor culto, mesmo já no final, o narrador solicita a opinião sobre o assunto.

Entre os dois contos, há semelhanças visíveis quanto à história e pela presença de protagonistas que são também narradores. Todavia, no que tange à concepção que os preside, há diferença fundamental: o narrador machadiano, dono de uma verdade que supõe ser científica, compraz-se em ilustrá-la com uma experiência pessoal. O de Guimarães Rosa, também a partir do relato de vivência própria, meticulosamente relatada, e em busca de explicações científicas e filosóficas, termina como começou: com dúvidas e perguntas.

Além disso, a imagem refletida do alferes é a sua "alma exterior", a sua máscara social, a representação para o e do outro. Embora o narrador machadiano mencione a existência de duas almas, só trata de uma, como comenta Dante Moreira Leite (1967, p. 194), alinhando-se aos críticos anteriormente citados:

Observe-se que, embora faça referência a duas almas, - uma que olha para dentro e outra que olha para fora, - a descrição apresentada no conto limita-se à alma externa, como se ambas pudessem reduzir-se à exterioridade [...] essa forma de descrever corresponde à concepção de Machado de Assis, segundo a qual a maior parte da vida mental é um processo de ajustamento às aparências sociais.

Por sua vez, John Gledson em "A história do Brasil em Papéis avulsos, de Machado de Assis” (2006, p. 71), relacionando ficção e história - embora ressaltando que, nos contos machadianos em que se inclui "O espelho", não se define "o enquadramento histórico" - afirma: "[...] aqui, mais do que nunca as especulações de Machado se centram na questão da identidade nacional que tão freqüentemente tem preocupado os intelectuais latinoamericanos desde a Independência." (p. 72). No caso específico da narrativa que nos ocupa, localiza a primeira referência histórica na menção ao espelho que a tia mandara colocar no quarto de Jacobina e que fora comprado de "uma das fidalgas vindas em 1808 com a corte de D. João VI". A referência à origem do espelho indicaria que as intenções do escritor não eram apenas filosóficas - problematizando as questões da alma e da identidade pessoal, pois, nesse caso, "qualquer espelho serviria". O estudioso de Machado 
(GLEDSON, 2006, p. 74), segue apontando o que, a seu ver, seriam reflexos da história na composição em pauta. Por exemplo, a identidade nacional seria imperceptível como o protagonista no espelho, ou seja, tal objeto "[...] é, ele próprio, um reflexo do que acontecerá mais tarde quando 'o alferes elimina o homem. Também Jacobina é um espaço vazio rodeado por uma moldura decorativa - o uniforme que ele veste para o impedir de desaparecer". No entanto, ressalta que, em "O espelho" e em outras narrativas como os romances Dom Casmurro e Quincas Borba, "A linguagem da psicologia (pré-freudiana) - sobretudo do inconsciente - encontra um lugar natural nessa original análise histórica." (p. 75).

Nesse ponto, o estudo de John Gledson aproxima-se do de Dante Moreira Leite (1967, p. 198), para quem o desmascaramento da alma exterior de Jacobina vincula o conto machadiano à teoria freudiana:

[...] a teoria de Machado de Assis contém outro elemento importante, correspondente à idéia de desmascaramento das aparências da pessoa. Essa tendência supõe uma oposição fundamental entre os impulsos individuais e as exigências da sociedade, a que a pessoa se submete. Essa tendência foi a que, - dentro evidentemente, de outras premissas teóricas, - encontrou expressão na teoria freudiana da personalidade.

A imagem do narrador rosiano, diferentemente daquela apresentada em "O espelho" de Machado de Assis, aparece horrenda, desfaz-se, desaparece e principia a reconstituir-se. É a alma mais profunda: composta do ancestral animal, dos resíduos dos antecedentes humanos, das paixões resultantes de pressões psicológicas e daquilo que é materialização das “idéias e sugestões de outrem", portanto, não é apenas exterior; é, no que diz respeito à psique humana, mais complexa do que a de Machado. A alma de Guimarães Rosa desmancha-se em "couve-flor" ou "bucho de boi" e, ao recompor-se, depois de ascese e sofrimento - como em "A hora e vez de Augusto Matraga" -, e já amando, emerge como "flor pelágica": a inocência do rosto infantil. Moreira Leite vê na onça a representação do ódio, o ser consumido pelo sofrimento. Por um lado, sem o ódio, o ser humano fica sem alma; por outro lado, a alma "verdadeira" é reencontrada com o amor. A "teoria” de Guimarães Rosa, segundo Moreira Leite (1967, p. 198), está próxima da teoria jungiana além de introduzir outros significados, não explicitados: 
Se passamos para "O espelho" de Guimarães Rosa, encontramos uma concepção psicológica que, sob alguns aspectos pelo menos, se aproxima da teoria jungiana de personalidade, embora introduza também outros conceitos. Ao contrário do que ocorre no conto de Machado de Assis, a exteriorização perde qualquer significado, e o herói-narrador procura devassar a sua intimidade, em busca de elementos fundamentais. Essa pesquisa conduz à descoberta de traços de ódio, mas, fundamentalmente, de ódio contra si mesmo. Quando elimina o ódio, o herói fica sem alma, pois esse sentimento seria o seu núcleo fundamental; só depois de um período de grandes sofrimentos é que o espelho começa a refletir um começo de luz, enquanto o rosto só aparecerá, - embora seja "rostinho de menino, de menos-que-menino, só", - depois do amor.

Há, também, no texto de Guimarães Rosa, uma relação entre a "arte de viver" e arte da arte, o processo criativo, naquilo que o escritor sempre propõe para a criação: o alijamento do que obstrui e soterra, os "ancestrais animais", os "antepassados", os "constrangimentos psicológicos", as "exigências alheias".

Contudo, no que diz respeito às personagens, os dois protagonistas, de Machado e de Guimarães Rosa, são "tentaculizados”, seduzidos pelo efeito especular que é a imagem refletida no espelho. Se compararmos - como faz Heloisa Vilhena de Araújo (1998) em relação a Guimarães Rosa - os protagonistas com o mito de Narciso e tomarmos como ponto de partida a reflexão sobre esse tema em A. Allejo (apud SILVA, 1995, p. 164-175), De como el proto-sujeito se agresiviza. El mito de Narciso, vemos que, nos três casos há a ação que encurta a distância que os leva à identificação com o outro especular. Como "Este intentar ser el otro de Narciso terminará con él, será la muerte de Narciso y el triunfo de lo especular" (ALLEJO, apud SILVA, 1995, p. 165). Narciso morre, tentando a identificação com a imagem que o seduz. É o núcleo da contradição do narcisismo: "para que a imagem pueda patentizarse como verdadera imagen tiene que morir lo real de Narciso." (ALLEJO, apud SILVA, 1995, p. 165). Segue a idéia de auto-agressividade: em toda relação especular estabelece-se um par em que um dos membros é dissolvido. Nos dois contos, passa-se da dissolução à recomposição da imagem. Narciso vê de pronto o Narciso belo - e é seduzido pela beleza que corresponde a padrões simbólicos, não por uma beleza qualquer.

Para Jacobina sobreviver, precisa ver-se num padrão de beleza aceito, padronizado como tal - o alferes; a personagem rosiana reencontra-se com a interioridade no rosto de menino, livre das injunções ancestrais, 
psicológicas, sociais. Tanto o narrador machadiano quanto o rosiano vêm borrões quando se afastam do ideal de beleza que abraçam. Seriam antinarcisos por evoluírem da morte narcísica - um, pela identificação com a beleza exterior; outro com a interior - que não leva à morte?

A aproximação e o afastamento no que diz respeito às vozes narrativas também devem ser considerados. Ambos os narradores enunciam ulteriormente os acontecimentos, tendo, sobre eles, aparentemente, domínio total. Todavia, em Machado, há dois narradores: o narrador heterodiegético (GENETTE, [198-], p. 244), delega a voz à personagem Jacobina, conhecedor do narrado. O que chama a atenção é o fato de a sua enunciação autodiegética fazer-se de modo claramente dialogado.

Em Guimarães Rosa, temos um narrador autodiegético, cujo relato se dá por diálogo implícito. Apesar de ser também dono absoluto dos fatos, é um narrador que, com a narração, quer recuperar o acontecido, entendê-lo, e, por meio dele, refletir sobre o seu significado. Na sua fala, os questionamentos se sucedem, não se resolvem, como em Grande sertão: veredas e outros escritos rosianos.

Por sua vez, Jacobina narra diegeticamente de modo tradicional, conclusivo. O relato de sua experiência - que pode ser considerada como "experimento científico" -, dá autoridade ao argumento inquestionável da alma exterior, questão cara a Machado de Assis, para quem a alma exterior é tudo.

$\mathrm{O}$ narrador rosiano, de um ponto de vista que também se quer científico e é ainda intuitivo - como, aliás, o protagonista machadiano -, segue etapas que se poderiam dizer científicas e tem respostas que a melhor ciência sempre dará: alguma certeza e muita dúvida. Para completarmos as observações de Moreira Leite, podemos acrescentar que a personagemnarradora não elimina apenas o ódio-onça, mas também os componentes hereditários, a paixão, o outro e o superficial. O caminho percorrido pelo protagonista rosiano é humanístico e místico - pelo sofrimento e amor a imagem se recompõe como deve ser: livre de todas as injunções.

Já no relato de Jacobina, é a experiência que ocorreu com ele que o autoriza a afirmar que, dependendo da relação que a pessoa estabelece com o Outro, a natureza da sua alma exterior é alterada. No presente, como os quatro cavalheiros que ouvem sua história, tendo entre quarenta e cinqüenta anos, a sua alma exterior, ou, pelo menos, uma parte dela, se espelha na opinião dos amigos que o vêem como casmurro "cuja espórtula no debate não passava de um ou outro resmungo de aprovação." (ASSIS, 1973, p. 25). 
O episódio relatado por ele exemplifica como a alma exterior sofre mudanças conforme a relação estabelecida com o Outro.

As várias denominações do protagonista machadiano refletem a natureza das diferentes almas exteriores construídas a partir de cada relação com o Outro. No momento presente da narração, Jacobina é tratado formalmente pelo seu sobrenome pelos companheiros de especulação. As características da personagem, que não admitia conjectura, opinião e que era casmurro estão contidas na denominação que recebe na idade madura. $\mathrm{O}$ sobrenome Jacobina remete, em primeiro lugar, aos Jacobinos, os parisienses partidários exaltados da democracia a partir de 1789 e, no Brasil, o termo passou a identificar os xenófobos, em especial os lusófobos (NASCENTES, 1955), os nacionalistas extremados (FERREIRA, 1999). Já a forma Jacobina que pode provir do tupi yakuabina e significa "terreno de cascalhos" (GUÉRIOS, 1973) e que, segundo Houaiss e Villar (2001), é um termo da Bahia que designa "terreno impróprio para a lavoura, coberto de mato baixo, cerrado e espinhoso". Citando Luiz Caldas Tibiriçá, a propósito do nome da cidade baiana, os dicionaristas registram outro significado para a palavra "espécie de árvore que perde as folhas por ocasião das secas" o que corrobora com o qualificativo intransigente, refratário que podemos atribuir às atitudes da personagem no momento da narração.

No tempo passado, as diferentes identificações de Jacobina demonstram o percurso da alma exterior de Joãozinho, hipocorístico carinhoso agregado ao nome João, que significa "cheio de graça" (GUÉRIOS, 1973), até chegar à idade adulta:

\begin{tabular}{|l|l|l|l|l|l|l|l|l|}
\hline \multicolumn{7}{|c|}{ PRESENTE } \\
\cline { 2 - 8 } \multicolumn{10}{|c|}{ PASSADO } \\
\hline $\begin{array}{l}\text { De } \\
\text { no } \\
\text { mi } \\
\text { na- } \\
\text { çôe } \\
\text { s }\end{array}$
\end{tabular}


Na leitura do "Esboço de uma nova teoria da alma humana" a partir das formas de tratamento que o Outro atribui ao protagonista, o apagamento do alferes começa a ocorrer quando a denominação dada por Tia Marcolina, "Senhor Alferes", é substituída por "Nhô Alferes" em que o Outro são os escravos que não tinham autoridade para referendar o papel social de alferes:

Era a alma exterior que se reduzia; estava agora limitada a alguns espíritos boçais. O alferes continuava a dominar em mim, embora a vida fosse menos intensa, e a consciência mais débil. Os escravos punham uma nota de humildade nas suas cortesias, que de certa maneira compensava a afeição dos parentes e a intimidade doméstica interrompida. (ASSIS, 1973, p. 30)

É Tia Marcolina, viúva do Capitão Peçanha, que mais reconhece o valor do posto do sobrinho e que martela no seu ouvido a palavra alferes como comenta o narrador "E sempre alferes; era alferes para cá, alferes para lá, alferes a toda hora." (ASSIS, 1973, p. 28). Referenda a figura de eco de Tia Marcolina a etimologia de seu nome. Guérios (1973) nos dá a chave para tal interpretação "Marcolina, diminutivo de Marcos, derivado de marcus 'grande martelo de ferreiro' que segundo L. Deroy provém de etrusco marce, 'martelador, ferreiro', da raiz mar, 'bater', 'ferir"'.

Quando até mesmo os escravos deixam o sítio, totalmente só, o eu, despojado do outro, encontra o EU, a alma interior, que sem o OUTRO é nada: "[...] porque a alma interior perdia a ação exclusiva, e ficava dependente da outra, que teimava em não tornar... E não tornava." (ASSIS, 1973, p. 33).

O preenchimento do eu dá-se no espelho, onde o eu desdobra-se no próprio EU que se espanta por não se reconhecer: "Olhei e recuei. O próprio vidro parecia conjurado com o resto do universo; não me estampou a figura nítida e inteira, mas vaga, esfumada, difusa, sombra de sombra." (ASSIS, 1973, p. 34).

O reconhecimento de si só acontece quando o $\mathrm{eu}^{2}$ exterior, o alferes, elimina o desconhecido eu1: "[...] era eu mesmo, o alferes, que achava, enfim, a alma exterior. Essa alma ausente com a dona do sítio, dispersa e fugida com os escravos, ei-la recolhida no espelho." (ASSIS, 1973, p. 35).

A alma de Jacobina, nas diferentes fases da sua vida, é de natureza social, tirando-lhe o que lhe é exterior, nada resta. Sob a aparência dos diferentes espelhos que são os outros, a alma interior não é passível de ser capturada. 
O conto rosiano, por sua vez, narra a busca da alma através da experiência do espelho. $\mathrm{O}$ percurso da personagem anônima não se centra no outro, mas no despojamento do seu EU, é a alma interna que lhe interessa conhecer: "Os olhos, por enquanto, são a porta do engano; duvide deles, dos seus, não de mim." (ROSA, 1972, p. 73).

Como em As aventuras de Alice no país das maravilhas e Através do espelho e o que Alice encontrou lá (1977), o anônimo não se contenta com sua imagem refletida e relata, no presente, quando já está mais velho, o que encontrou na experiência vivida na mocidade. Em queda em rodopio de fora para dentro vê-se de frente com o "EU que sou o OUTRO":

E o que enxerguei, por instante, foi uma figura, perfil humano, desagradável ao derradeiro grau, repulsivo senão hediondo. Deu-me náusea, aquele homem, causava-me ódio e susto, eriçamento, espavor. E era - logo descobri... era eu, mesmo! (ROSA, 1972, p. 73)

Na busca do EU “por trás de mim”, da sua essência, da "vera forma”, o "sósia inferior na escala era, porém - a onça" (ROSA, 1972, p. 35) e a desfigura. Somente depois do sofrimento consegue vislumbrar uma radiância e, enfim, quando ama se configura, renascido, em um rosto de menino.

No texto rosiano, o conhecimento do EU depende do encontro com a alma interior, que acontece como uma queda em rodopio para dentro de si e que, em um afunilamento, chega ao final do túnel onde o que resta é "[...] o julgamento-problema, podendo sobrevir com a simples pergunta: - "Você chegou a existir?" (ROSA, 1972, p. 78, grifo do autor):

O texto machadiano, que se assemelha a um ensaio, em que Jacobina exemplifica de maneira didática o esboço de uma nova teoria da alma humana, defende que se pode mudar constantemente de espelho, dependendo da relação que se estabelece com o OUTRO. Demonstrada à forma de um teorema, para a nova teoria, conhecer a si é ser conhecido pelo OUTRO. Como dito, o texto cria um efeito de verdade que espelha a crença machadiana na supremacia da sociedade em relação ao indivíduo.

Diferentemente, a experiência através do espelho da narrativa rosiana deixa-nos a dúvida sobre como se encontrar o verdadeiro EU, configurada no "julgamento-problema”: - "Você chegou a existir?", que condensa a crise existencial do século XX. 


\section{Referências Bibliográficas}

ALBERGARIA, Consuelo. Bruxo da linguagem no Grande sertão: leitura dos elementos esotéricos presentes na obra de Guimarães Rosa. Rio de Janeiro: Tempo Brasileiro, 1977.

ARAUJO, Heloisa Vilhena. O espelho: contribuição ao estudo de Guimarães Rosa. São Paulo: Mandarim, 1998.

ASSIS, Machado de. O espelho. In: GOMES, E. (Org.) Machado de Assis: contos. Rio de Janeiro: Agir, 1973.p. 137-144 (Coleção Nossos Clássicos).

BOSI, Alfredo. O enigma do olhar. São Paulo: Ática, 1999.

CANDIDO, Antonio. Esquema de Machado de Assis. In: - Vários escritos. São Paulo: Duas Cidades, 1970. p. 13-32.

CARROLL, Lewis. As aventuras de Alice no país das maravilhas e Através do espelho e o que Alice encontrou lá. Rio de Janeiro: Summus, 1977.

GENETTE, Gérard. Discurso da narrativa. Lisboa: Vega, [198-].

FERREIRA, Aurélio Buarque de Holanda. Novo Aurélio século XXI: o dicionário da língua portuguesa. Rio de Janeiro: Nova Fronteira, 1999.

GLEDSON, John. Por um novo Machado de Assis: ensaios. São Paulo: Companhia das Letras, 2006.

GOMES, Eugênio. Apresentação. In: . (Org.) Machado de Assis: contos. Rio de Janeiro: Agir, 1973. p. 5-18 (Coleção Nossos Clássicos).

GUÉRIOS, Rosário Fârani Mansur. Dicionário etimológico de nomes e sobrenomes. São Paulo: Ave Maria, 1973.

HOUAISS, Antônio e VILLAR, Mauro de Salles. Dicionário Houaiss da língua portuguesa. Rio de Janeiro: Objetiva, 2001.

LEITE, Dante Moreira. Retratos e espelhos. In: . Psicologia e literatura. 2. ed. São Paulo: Nacional/ EDUSP, 1967. p. 192-198.

MEYER, Augusto. Machado de Assis. Rio de Janeiro: Presença, 1975.

NASCENTES, Antenor. Dicionário etimológico da língua portuguesa. Rio de Janeiro: Livraria Acadêmica, 1955. 
PACHECO, Ana Paula. Lugar do mito: narrativa e processo social nas Primeiras estórias de Guimarães Rosa. São Paulo: Nankin, 2006.

ROSA, João Guimarães. Estas estórias. Rio de Janeiro: José Olympio, 1969.

ROSA, João Guimarães. Grande sertão: veredas. Rio de Janeiro: José Olympio, 1968.

ROSA, João Guimarães. Primeiras estórias. Rio de Janeiro: José Olympio, 1972.

ROSA, João Guimarães. Sagarana. Rio de Janeiro: José Olympio, 1965.

SILVA, Ignácio Assis. Figurativização e metamorfose: o mito de Narciso. São Paulo: Ed. UNESP, 1995. 